\title{
Perceptions of University Assessment and Feedback Among Post-16 School Pupils
}

${ }^{\mathrm{a} J o n e s, ~ H a r r i e t ~ L J *}{ }^{*},{ }^{\mathrm{a}}$ Yeoman, Kay, ${ }^{\mathrm{a}}$ Gaskell, Emma, ${ }^{\mathrm{b}}$ Prendergast, John R

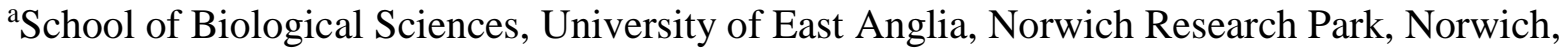
NR4 7TJ

tel 01603456161

e-mails: harriet.jones@uea.ac.uk k.yeoman@uea.ac.uk emma.gaskell@hotmail.co.uk

bJRP Information Services, Lymington, Hants, SO41 0ZP e-mail:

jrprendergast@gmail.com

*Corresponding author: Harriet.jones@uea.ac.uk

This work was supported by the Higher Education Academy through a grant awarded in 2005. 


\begin{abstract}
The transition between school and university can be problematic for students. Understanding students' expectations about the system they are entering into is crucial in effecting a smooth transition. The school system involves small classes, often with teachers who know their students well. In contrast university involves large class sizes and a degree of anonymity for the student. In the UK National Student Survey responses for universities show that students are generally less happy about feedback relative to most other issues. The current study investigates school students' expectations about assessment and feedback practices at university. Students were surveyed across Great Britain in 2006 and 2013. There were some significantly different responses from students between the two years of study in how coursework would be handled, but there were also many areas of consistency, demonstrating a clear pattern of expectation. For example, in both years of study $80 \%$ of students expected personal verbal feedback on their university assignments. This study discusses how student expectations may be based on their school experiences rather than considering the reality of the university system they are entering into. Misconceptions may be affecting students' responses to the NSS surveys on assessment and feedback.
\end{abstract}

Key Words: feedback, assessment, perceptions, transition 


\section{Introduction}

The school to university transition is recognised as a challenging and unsettling period fraught with potential difficulties (Slaughter and Bates 2009). Consequently, adjustment to university life, student satisfaction and successful completion of the first year in particular is far from certain (Cook and Leckey 1999). A relationship between student perceptions, approach to study and academic outcome has been described (Bedford and O'Brien 2012). Adjustment, engagement and retention can be negatively influenced by unrealistic student expectations (Baxter and Hatt 2000), highlighting a need for greater understanding between students and faculty at the beginning of an academic programme (Byrne and Flood 2005).

During the past two decades, the UK higher education sector has had to respond to a large number of externally driven government-led changes (Dearden, Fitzsimons, and Wyness 2011). This has not only encouraged wider access and greater participation in higher education (Crabtree, Roberts and Tyler 2007) with a wider array of student educational experiences (Wingate 2007), but has also driven a potential shift towards a commercial setting (Wilkins, Shams and Huisman 2013) in which the students are the customers and the university is the service provider (Sander et al. 2000). Institutions keen to raise their reputation within a highly competitive market may opt to do so by improving student retention rates through the targeting of misalignment between students' academic and social expectations and their first-year experiences (Crisp et al. 2009). Ultimately, students' expectations need to be addressed in order to better match the reality of the university experience or changes in approaches to student engagement must be made to better match the students' needs (Longden 2006).

Previous investigations have identified the importance of student expectations and have shown that controlled management of the views of students from traditionally 
disadvantaged groups can positively affect retention and performance (Steele 1992). With potential for measurable improvements in student outcomes, discovering more about student expectations and preferences for teaching styles they are likely to encounter could be valuable information for higher education institutions (Sander et al. 2000). In the National Student Survey (NSS) students in the UK have been notably less positive about assessment and feedback on their assignments than about other aspects of their course experience (Williams and Kane 2008). This knowledge may help direct the design of strategies aimed at addressing student expectations and the possible evolution of programmes that have improved efficacy and are well received (Stevenson and Sander 1998).

There is growing global scholarly concern that students are inadequately prepared for university courses (Trotter and Roberts 2006) and it has been suggested that this has contributed to declining university standards and high failure rates (EMBO 2006) (European Molecular Biology Organisation). Throughout their school careers, students are tutored, assessed and receive instruction within a carefully controlled environment in which the requirements of syllabuses and limits of desired knowledge are well defined (Surgenor 2013). This is in contrast to the system within higher education (Jessen and Elander 2009). Such a shift is commonly associated with a lack of preparedness for autonomous active learning. It is suggested that students are failing to make the crucial transition between school and university either quickly or effectively (Lowe and Cook 2003). Worries about inexperience of independent learning and unrealistic expectations concerning university education have also been expressed by students themselves (Leese 2010).

Over the last few decades there has been a widely-reported decline in the academic abilities with which students are entering university and this may well be attributable to changes in the structure and demands of the modern A-level course (Fee, Greenan and Wall 2009). There is a belief amongst many UK education commentators that students' responses 
in exams have become formulaic and reliant on rote learning (Daly et al. 2012). School education is no longer designed as a preparation for university (Browning and Sheffield, 2008), with a focus on exam performance at the expense of learning how to gather information and develop critical evaluation skills (Julien and Barber 2009). Slaughter and Bates (2009) showed a decline in students' levels of expert-like thinking in a range of categories, including problem solving, personal interest and real world connections, whilst previous studies of new undergraduates concluded that students failed to adapt learning strategies for the higher cognitive demands of higher education (Broekkamp and Van HoutWolter 2007).

The former Labour government introduced a number of policies seeking to tackle these issues in the Education and Skills White Paper (Department for Education and Skills [DfES] 2005). This led to the introduction, in 2008, of the Extended Project Qualification (or EPQ, a project-based qualification for sixth form students which involves researching and addressing a research question) and the 'stretch and challenge' approach designed to add depth and breadth to the curriculum and academically push the most capable students. A more recent white paper (Department for Education 2010) stated a desire to explore how Alevels can provide deep synoptic learning while actively comparing the performance of UK pupils against international benchmarks (Daly et al. 2012). However, fears remain that the growing pressure to get students into university may be encouraging school teachers to alter the way in which they offer guidance, thus enhancing students' misperceptions of tuition in higher education (Brinkworth et al. 2009). There has since followed a reformation of many A-level courses with the intention of making them a better preparation for higher education. This has been done in part by including universities in the design of content. There has also been a drive towards formal examinations at the expense of coursework assessments in many of the subject areas (Wilson, Child and Suto 2016). 
Research into student retention attributes lower levels of university completion and higher levels of first year withdrawals to a lack of 'academic preparedness' (Yorke and Thomas 2003). It has been argued that, whilst a student's school achievement is a positive (yet weak) predictor of their university achievement (Lizzio, Wilson and Simons (2002), perceptions of university learning environments make a clear contribution to academic outcomes above the prior academic success of a student (Kreber 2003). A successful transition depends on the ability to make a rapid adjustment to a learning environment that requires greater autonomy and individual responsibility than students typically expect upon commencement (Brinkworth et al. 2009).

Although there have been many investigations into the experience of first year undergraduates, few studies have focused on the expectations of students prior to commencing their university studies (Miller, Bender and Schuh 2005). The current study explores the perceptions of assessment and feedback at university among students across Great Britain in the last two years of their school education. The study of schools in 2006 was funded by an HEA (Higher Education Academy) award leading to a report for the HEA (Jones et al. 2009). The current study extends this work by looking at the results from 2006 in relation to the same questions to students in 2013. While looking at perceptions of assessment and feedback, the study is also looking at changes between the 2006 and 2013 cohorts.

\section{Methods}

The methodology was questionnaire-based, with guided discussions held to assist in the design of the final questionnaires. All questionnaires and guided discussions were passed by the University of East Anglia (UEA) ethics committee in 2005. 
A small-group structured interview was carried out with fifteen Year 12 students from two state secondary schools in East Anglia. The pupils were studying at least one science subject at A-level and were aiming to continue on to higher education. The interview covered topics relating to how they were being taught at school and how they anticipated being taught at university. Questions were open-ended, such as those used by Buswell and Matthews (2004), to enable unanticipated topics to emerge. The results from this interview were used to structure a pilot questionnaire, similar to the method used by Crook, Gross and Dymott (2006). This questionnaire was taken to one of the two schools, where twelve Year 13 students, who were taking Biology A-level, were individually taken through the questionnaire and their interpretation of each question was discussed with them. The questionnaire was rewritten where appropriate and piloted at the second of the two schools, where it was given to twelve Year 13 pupils as a group. They completed the questionnaire and then discussed it as a group. Minor changes were made to the questionnaire following this process.

The responses of the students in the pilot helped design a questionnaire that was circulated to participating schools in England, Scotland and Wales. There was a mixture of state and independent schools in both years of study. School teachers managed the collection of data, typically done at registration period. The completed questionnaires were returned to the School of Biological Sciences at UEA.

The final questionnaire included several different styles of question: 'yes'/'no' answers; answers that used the Likert scale; and ranking statements in order of preference. Some questions were modelled on those that ask specific questions with 'strongly agree' to ‘strongly disagree' response options, such as those used by Gibbs \& Simpson (2003). Some key subjects were covered by several different question types to maximise their usefulness. 
This questionnaire was distributed to 31 schools in 2006 and seven schools in 2013. Schools were selected to represent a range of types of school (state and independent) and geographical variation to include England, Scotland and Wales. They were recruited through personal contacts of the authors of this study. The majority were state schools, but private day schools and boarding schools were included. The only stipulation was that pupils must be taking at least one science subject at A-level. The questionnaire was translated into Welsh for the one Welsh-speaking school in the study, and adapted for those at schools in Scotland taking Scottish Highers. The questionnaire was paper-based and either taken or posted to specific identified teachers in each school. Arrangements were made for the completed questionnaires to be either returned by post or collected by hand. Questionnaires which were defaced or had suspiciously uniform answers were discarded from the analysis. The total number of questionnaires used in this study were 641 from 2006 and 853 from 2013, sampling approximately $0.1 \%$ of the total sixth form population.

All data from the questionnaires were entered onto separate Microsoft Access databases and then amalgamated onto a single Access database to allow comparisons of all information so that responses could be compared across a range of different categories. For all questionnaires, the number of responses to each question was recorded individually, so that if one question was not answered, the questionnaire was still included for analysis for all other questions. For example, this might be the case where students were asked about sciences vs non-science subjects. If students had no experience of Arts subjects and left relevant questions blank, the rest of their responses were included in the analysis. For questions that involved the ranking of responses, only those questionnaires where the whole question was completed as required were included in the analysis.

For the analysis of Likert scale data, the Chi squared test was used to identify a) overall differences between the two years, for individual questions and b) differences 
between responses for individual questions, for either separate or combined years, as appropriate. To be deemed significant the $\mathrm{p}$ value had to be $<0.05$.

\section{Results}

Students were asked about the nature of the verbal feedback they were given at school and what type of feedback they would expect when at university. When asked whether they agreed with the statement relating to their future university assignments: I expect to have some personal verbal feedback about how I have done in the assignment, $80.4 \%$ totally agreed or partially agreed with this statement. Similarly $70.0 \%$ of students totally or partially agreed that with the statement I expect to have some verbal feedback, given to the whole class, about the assignment. At school, in science subjects, there was a difference between the 2006 and 2013 cohorts with the 2006 cohort reporting receiving more verbal feedback than the 2013 cohort (Figure 1) (Chi sqd $=49.94$, d.f. $=1, \mathrm{p}<0.005)$.

In non-science subjects there was no difference between the two years in the percentage of students getting verbal feedback at school (Chi sqd $=2.04$, d.f. $=1$, NS). In nonscience subjects $90.5 \%$ of students reported 'sometimes' 'often' or 'always' getting verbal feedback at school (Figure 2). In science subjects this was slightly lower (78.9\%) (Figure 1).

Students were asked about their expectations of verbal feedback in a range of scenarios at university (Table 1). Results were fairly consistent with over $50 \%$ of students 'always' or 'often' expecting all types of verbal feedback listed.

Students were asked about the use of material from the internet in assignments. While almost all students, from both cohorts, partially or totally agreed with the statement At school, 
when essays are marked, I would lose marks if I did not put material from the internet in my own words, when asked whether they would lose marks if they did this, significantly more students totally agreed in the 2006 cohort than the 2013 cohort (Figure 3) (Chi sqd $=48.59$, d.f. $=4, p<0.005)$.

Looking at students' perceptions of how this would be handled at university, students were asked to rank which errors would be most heavily penalised. In the 2006 cohort $52 \%$ of students ranked copying material directly from the internet into an essay first, whereas the 2013 cohort only $41 \%$ ranked it first. In this later cohort more students (45.6\%) ranked first failing to directly answer the question/assignment title relative to the 2006 cohort $(32.8 \%$, Chi sqd $=24.18$, d.f. $=1, \mathrm{p}<0.005)$.

Data were gathered on students' views on whether a draft of their assignment was commented on at school before a final version was submitted. In non-science subjects there was no difference in response percentages between the two cohorts, but when students were asked At school, in science subjects, how often is a draft commented on before you hand in a final version, from the 2006 cohort over $48.2 \%$ said 'always' or 'often' (very similar to the percentage for non-science subjects) but in the 2013 cohort only $17.0 \%$ gave this response (Figure 4) $($ Chi sqd $=158.73$, d.f. $=1, \mathrm{p}<0.005)$.

However, when looking at perceptions of how work would be handled at university there were no significant differences in responses between the two cohorts. Combining results for both cohorts and where students were responding about practical reports and essays, approximately $25 \%$ of students partially or totally disagreed that they expected a lecturer to read and correct a draft before a final version was submitted. In a similar question, students were asked if at university, if an essay is set, how often do you expect a draft to be commented on before you hand in a final version. In the 2006 cohort about $30 \%$ said rarely 
or never compared to $12 \%$ in the 2013 cohort (Figure 5) (Both cohorts combined - Chi sqd = 36.96, d.f. $=1, \mathrm{p}<0.005)$

Students were asked about how strictly deadlines were adhered to. There were no significant differences between the cohorts and the greatest percentage answered 'often' for school and 'always' for university (Figure 6). However, when the cohorts were combined and the data for school and university were compared, it was at school where the greatest adherence to deadlines was expected $($ Chi sqd $=159.64$, d.f. $=1, \mathrm{p}<0.005)$. Differences were seen between the two cohorts when asked whether they expected all assignments to be assessed. There was less agreement in the 2006 cohort than the 2013 cohort (Figure 7). Similarly, when asked about who marks the assignment, there was greater agreement that it would be the person who set the work among the 2013 cohort than the 2006 cohort (Figure 8).

Students were asked to rank the type of feedback in the order that they would consider it most valuable. There were no significant differences between the two cohorts. The highest percentage of students ranked verbal feedback as the feedback most valuable to them and least was corrections to spelling and grammar (Table 2).

\section{Discussion}

Differences were observed between the two cohorts of students questioned in this study. For example, a greater proportion of the 2006 cohort reported receiving verbal feedback in science subjects than the 2013 cohort $(\mathrm{p}<0.005)$. Similarly, a significantly greater number of students in 2006 reported often or always getting feedback on a draft before submitting the final version than in 2013 ( $\mathrm{p}<0.005$ ). This appears to be reflecting changes in school practice 
over the seven years between these two studies. A possible explanation for these differences may be the changes made to the teaching and assessment of A-levels in accordance with the government white papers (Department for Education and Skills, 2005; Department for Education, 2010). Brown, Harris and Harnett (2012) studied schools in New Zealand but compared their data to British assessment practices in schools. They reported a change to more 'in-the-moment interactions' which could possibly account for less emphasis on feedback to assignments observed in the 2013 cohort of this study They also suggested that, as the emphasis on external measures has increased, the role of feedback in terms of learning has decreased, while emphasis on grade achievement has increased.

The way that assessment and feedback is handled will vary both within and between schools as well as between the two cohorts studied. The proportion of the total number of sixth form students sampled in this study was relatively low (approximately $0.1 \%$ ), but the sample size was large and standard errors small, so the mean values in the study can be taken as representative of the population. Variation in the type of subjects students studied will have affected their ability to answer some of the questions where, for example, students were asked about practices in science or non-science subjects. When data was entered, some students left some questions blank and it was taken that this was where students had no experience to answer the question. This was never above $1 \%$ of the sample size though.

A greater percentage of students in 2006 'rarely' or 'never' expected a draft essay to be commented on at university than the 2013 cohort (Chi sqd $=36.96$, d.f. $=1$, $p<0.005$ ). So the expectations of the 2013 were possibly less realistic than the 2006 cohort. This may be influenced by the introduction of tuition fees and the possible effect this has had on student expectations regarding the level of service they receive at university (Wilkins, Shams and Huisman 2013). When carrying out the small group discussions with the 2006 cohort, to design the questionnaires, it became apparent that students had not directly considered issues 
such as feedback to coursework at university. Donnelly (2015) discusses hidden messages within school teaching which might influence students' thoughts on higher education. She discusses this in relation to choice of Higher Education institution. Her reasoning may well be relevant here in looking at school pupils' perceptions of higher education. In school students may be picking up messages about higher education practices, and this will also relate to changing practices within their own schools. Any change in student expectations may also relate to government amendments to school education policy (Ball 2013).

Plagiarism is an area of increasing concern in higher education (Owens and White 2013). Whilst students from both cohorts deemed copying material from the internet without putting it into their own words to be unacceptable for school essays, when asked whether they would lose marks if they did this, a significantly larger proportion of students totally agreed in the 2006 cohort than the 2013 cohort. In the 2006 cohort, $52 \%$ of students ranked copying material directly from the internet into an essay as the error that they would be most severely penalised for, whereas in the 2013 cohort only $41 \%$ ranked it first. In this later cohort more students (45.6\%) ranked failing to directly answer the question/assignment title first relative to the 2006 cohort $(32.8 \%$, Chi sqd $=24.18$, d.f. $=1, \mathrm{p}<0.005)$. This indicates a lack of awareness of the issues and repercussions of plagiarism in higher education, as discussed by Lori (2009). The differences observed here may also be related to the rapid development in technology, the accessibility of the internet as a highly valued and widely accepted information source and the ease with which information can be copied and stored (Owunwanne, Rustagi and Dada 2010).

There were no significant differences between the two cohorts when students were asked to rank feedback type by order of importance. Mulliner and Tucker (2015) found that students in their study preferred verbal to written feedback. Whereas, the present study showed no preference between verbal and written comments in students' first choice of 
feedback, and when combining first and second choices, written feedback was rated higher than verbal feedback. Corrections to spelling and grammar was given least priority. The rise of the use of texting and other abbreviated language may have some baring on this lack of value associated with feedback on spelling and grammar. The type of feedback valued by students may be shaped by student habituation to a style of learning and assessment that schools develop in order to meet the demands of the curriculum. Indeed, A-level teaching continues to be the subject of much scrutiny with critics arguing that a change of emphasis from seeking marks to developing suitable learning approaches would provide students with a greater ability to analyse, think critically (Harris and Harris, 1995) and understand what is expected of them when preparing assignments at university (Crook, Gross and Dymott 2006).

Large discrepancies have been documented between the expectations of students in their first year of higher education and those of their tutors (Yorke and Longden 2008). Mulliner and Tucker (2015) asked students about their perceptions of feedback and found that they were expecting personal verbal feedback from teachers. This supports the present study where $80 \%$ of students were expecting personal verbal feedback from their lecturers. It might seem unrealistic of these students but according to Mulliner and Tucker (2015) perception from university staff is that students are offered personal feedback, the difference being that students at university have to actively seek it. They found staff rated personal feedback even higher than students but that workload of lecturers may be an important factor in determining why students didn't often get this personal verbal feedback. Yet, the university system, with large numbers of students and the desire to treat everyone fairly, generally offers little or no personal contact between the marker and the student during the feedback process (Crook, Gross and Dymott 2006). At school students are in small groups in a classroom with their teacher where they might receive personal verbal feedback, in contrast to the university environment where students are rarely in this setting. The environment in 
which feedback is offered may well be as important as the feedback itself. This further highlights a need for rapid implementation of financially and logistically feasible strategies that prepare and enable students to engage and integrate fully in their new environments without the difficulties and confusion brought about by potentially unrealistic expectations.

Students regularly enter higher education with inaccurate preconceptions of what to expect and what is expected of them from a teaching, learning and assessment perspective (Surgenor 2013). This may be related to the nature of student educational histories and has implications for pre-university preparation, undergraduate satisfaction and long-term academic success (Brinkworth et al. 2009). Schools can give messages to their pupils about what to expect at universities either intentionally or unintentionally. Donnelly (2015) studied this in relation to choices students made about which Higher Education establishments to apply for, and it could be considered equally relevant to what students expect the teaching and learning environment to be like when they get there. Addressing the gap between expectation and subsequent experience is associated with a positive effect on student satisfaction and retention (Long, Ferrier and Heagney 2006).

With a greater variety of students accessing higher education, the range of expectations will undoubtedly increase. However, whilst the formation of student expectations of higher education are complex and multi-factorial (Lumsden, McbrydeWilding and Rose 2010) it is argued that the strongest influencing factors are cognitive and psychological, with socioeconomic differences and types of institution accounting for little variance in expectations (Kuh, Gonyea and Williams 2005). Despite an absence of demographic details, the data provided here may prove highly valuable in helping universities to better understand student needs and the areas of learning that require more detailed explanation prior to commencement of teaching. This knowledge can be used to further facilitate an educational approach that prepares and supports school students in becoming 
independent learners, who actively engage with their subject area and have the skills to adapt to new demands and meet new challenges (Lumsden, Mcbryde-Wilding and Rose 2010).

Strong relationships have been demonstrated between student approaches to studying and perceptions of the learning environment (Entwistle, McCune and Hounsell 2002). However, Brinkworth et al. (2009) strongly suggest that the progression from secondary to higher education is problematic and remains fraught with uncertainty. Rather than prompting a negative appraisal of student abilities, greater understanding of this can offer an opportunity to set about facilitating the transition. Flexible learning and teaching strategies are crucial (Lumsden, Mcbryde-Wilding and Rose 2010). Just as students may hold misconceptions, so universities may make inaccurate assumptions about students' requirements and awareness (Pithers and Holland, 2006). Strategies to improve the situation have been put forward. The importance of university visits both from and to schools in order to further assist in communication, understanding and information flow has been previously emphasised (Bedford and O'Brien 2012). Crisp et al. (2009) believe that students would also benefit from greater discussion of the concept of self-directed learning and evaluation. Surgenor, (2013) suggests that student confusion over assessments and learning techniques could be reduced with development of the module descriptor as an information tool.

Assessment and feedback are fundamental to the student learning experience and the National Student Survey (NSS) and the Quality Assurance Agency (QAA) have identified both as crucial areas in need of improvement (Jones et al. 2009). Students appear to have strong opinions about their expectations with regard to feedback, but it comes with very variable quality (Brown, Harris and Harnett 2012). Developing an understanding of student perceptions is imperative in order to target the key issues in an effective manner. It is reported that students with unrealistic perceptions of a learning environment are more likely to follow a shallow approach to learning (Marton and Saljo 1976). In addition, where the 
focus is on the application of knowledge, as it is in higher education, rather than merely reproducing information which is more recognised as a school approach, problems associated with the transition from one environment to the other can limit student learning outcomes and success (Lizzio, Wilson and Simons 2002).

Student expectations of learning, teaching and assessment in higher education can strongly influence levels of student satisfaction, retention and academic success (Crisp et al. 2009). This study shows that students value personal contact with their teachers and expect this to continue when they move from school to higher education. The stresses and difficulties associated with the transition from secondary to higher education may be alleviated by addressing these expectations. Jones et al. (2009) report an intervention where incoming students were told about differences between school and university assessment and feedback. Such an intervention can help students understand why university practices may differ from their expectations and this in turn may help improve student evaluation of university feedback practices. Universities are therefore advised to use data, such as is presented in this paper, to let students know that the environment they are entering is aware of their perceptions of how assessment and feedback is handled in Higher Education. Being explicit about how university practice differs from these perceptions, and why, should help students in making the transition to higher education.

It may be possible that one of the reasons for low feedback scores in the NSS may be because of a mismatch between student expectation and the reality of university systems. Equipping students with an understanding of how their perceptions may not match the practices they will experience in higher education, and why this is the case such as large class sizes, may be the key to helping them make a smooth transition and more positive evaluation of the feedback practices they encounter. And while there were some differences between cohorts in this study, key issues such as expecting personal verbal feedback, and expecting a 
draft to be commented on before submission, were consistent across the years. Student expectation of the university feedback and assessment process appears to be entrenched in our system and requires acting on both before and after they arrive at university.

\section{References}

Ball, S. 2013 The Education Debate: Policy and Politics in the Twenty-first Century (2nd Ed) (Bristol: Policy press).

Baxter, A. \& Hatt, S. (2000) Everything must go! Clearing and first year performance, Journal of Further and Higher Education, 24 (1), 5-14. DOI:10.1080/030987700112273

Bedford, S. B. \& O'Brien, G. (2012) A view of first year transition from Down Under, New Directions, 8, 53-57.

Brinkworth, R., McCann, B., Matthews, C. \& Nordstrom, K. (2009) First year expectations and experiences: student and teacher perspectives, High Education, 58, 157-173. DOI: $10.1007 / \mathrm{s} 10734-008-9188-3$

Broekkamp, H., \& Van Hout-Wolters, B. (2007). Students' adaptation of study strategies when preparing for classroom tests. Educational Psychology, 19, 401-28. DOI: $10.1007 / \mathrm{s} 10648-006-9025-0$

Brown, G. T.L., Harris, L. R. \& Harnett, J. (2012) Teacher beliefs about feedback within an assessment for learning environment: Endorsement of improved learning over student wellbeing, Teaching and Teacher Education, 28, 968-978. DOI: 10.1016/j.tate.2012.05.003 
Browning, C. and Sheffield, S. L. (2008) Practice makes perfect? University students' response to a first year transition course. Collected Essays on Learning and Teaching, 1, 2227

Buswell, J. and Matthews, N. (2004) Feedback on feedback! Encouraging students to read feedback: a University of Gloucestershire case study. Journal of Hospitality, Leisure, Sports and Tourism Education. 3 (1), pp.61-7. DOI: 10.3794/johlste.31.63

Byrne, M. \& Flood, B. (2005) A study of accounting students' motives, expectations and preparedness for higher education, Journal of Further and Higher Education, 29 (2), 111124. DOI: $10.1080 / 03098770500103176$

Cook, A. \& Leckey, J. (1999) Do Expectations Meet Reality? A survey of changes in firstyear student opinion, Journal of Further and Higher Education, 23 (2), 157-171. DOI: $10.1080 / 0309877990230201$

Crabtree, H., Roberts, C. \& Tyler, C. (2007) Understanding the problems of transition into higher education. Available online at: http://www.ece.salford.ac.uk/proceedings/papers/35_07.pdf (accessed 4 July 2014)

Crisp, G., Palmer, E., Turnbull, D., Nettelbeck, T. \& Ward, L. (2009) First year student expectations: Results from a university-wide student survey, Journal of University Teaching \& Learning Practice, 6 (1), 8-26.

Crook, C., Gross, H. \& Dymott, R. (2006) Assessment relationships in higher education: the tension of process and practice, British Educational Research Journal, 32 (1), 95-114. DOI: $10.1080 / 01411920500402037$ 
Daly, A., Baird, J., Chamberlain, S. \& Meadows, M. (2012) Assessment reform: students' and teachers' responses to the introduction of stretch and challenge at A-level, The Curriculum Journal, 23 (2), 139-155. DOI: 10.1080/09585176.2012.678683

Dearden, L., Fitzsimons, E. \& Wyness, G. (2011) The impact of tuition fees and support on university participation in the UK (London: Institute for Fiscal Studies (IFS))

DOI:10.1920/wp.ifs.2011.1117

Department for Education. 2010. The importance of teaching. (London: Department for Education)

Department for Education and Skills. 2005. 14-19 Education and Skills. (London: Department for Education and Skills).

Donnelly, M. (2015) Progressing to university: hidden messages at two state schools, British Educational Research Journal, 41(1), 85-101. DOI: 10.1002/berj.3136

EMBO (2006) From School to University: A Report on the Transition from Secondary School Biology, (Germany: European Molecular Biology Organization). Available online at: http://www.anisn.it/matita_allegati/pdf/report\%20EMBO\%202006.pdf (accessed 12 January 2015).

Entwistle, N., McCune, V. \& Hounsell, J. (2002) Approaches to Studying and Perceptions of University Teaching-Learning Environments: Concepts, Measures and Preliminary Findings (Edinburgh: ETL Project). Available online at: http://www.etl.tla.ed.ac.uk//docs/ETLreport1.pdf (accessed 15 January 2015) 
Fee, H., Greenan, K. and Wall, A. (2009) An investigation into secondary school exit standards: implications for university lecturers.” International Journal of Management Education 8 (2): 43-52. DOI: 10.3794/ijme.82.269

Gibbs, G. and Simpson, C. (2003) Measuring the response of students to assessment. Paper presented at: 11th Improving Student Learning Symposium. Hinckley, England, 1-3 September

Harris, N. and Harris, A. (1995) Doing more with less: improving the quality of the first year experience on Business undergraduate courses within the context of a diminishing resources base. Journal of Further and Higher Education. 19 (3), pp.63-73. DOI:

10.1080/0309877950190306

Jessen, A. \& Elander, J. (2009) Development and evaluation of an intervention to improve, Journal of Further and Higher Education, 33 (4), 359-380. DOI:

$10.1080 / 03098770903272461$

Jones, H., Bavage, A., Gilbertson, A., Gorman, M., Lodge, J., Phillips, K. \& Yeoman, K. (2009) Increasing the quality of feedback on assignments while altering student perceptions of good feedback based on their school experience (York: The Higher Education Academy). Available online at: https://www.heacademy.ac.uk/sites/default/files/jones_final_report.pdf (accessed 16 January 2015)

Julien, H. and Barber, S. (2009) How high-school students find and evaluate scientific information: A basis for information literacy skills development. Library and Information Science Research, 31, 12-17 DOI: 10.1016/j.lisr.2008.10.008 
Kreber, C. (2003) The Relationship between Students' Course Perception and their Approaches to Studying in Undergraduate Science Courses: A Canadian experience, Higher Education Research \& Development, 22 (1), 57-75. DOI: 10.1080/0729436032000058623

Kuh, G., Gonyea, R. \& Williams, J. (2005) What students expect from college and what they get. In: T. Miller, B. Bender, \& J. Schuh (Eds) Promoting reasonable expectations: Aligning student and institutional thinking about the college experience (San Francisco: Jossey-Bass).

Leese, M. (2010) Bridging the gap: supporting student transitions into higher education, Journal of Further and Higher Education, 34 (2), 239 - 251. DOI:

$10.1080 / 03098771003695494$

Lizzio, A., Wilson, K. \& Simons, R. (2002) University Students' Perceptions of the Learning Environment and Academic Outcomes: Implications for theory and practice, Studies in Higher Education, 27 (1), 27-52. DOI: 10.1080/03075070120099359

Long, M., Ferrier, F. \& Heagney, M. (2006) Stay, play or give it away? Students continuing, changing or leaving university study in their first year (Clayton: Monash University ACER). Available at: http://files.eric.ed.gov/fulltext/ED505791.pdf (accessed 17 January 2015).

Longden, B. (2006) An Institutional Response to Changing Student Expectations and their Impact on Retention Rates, Journal of Higher Education Policy and Management, 28 (2), 173-187. DOI:10.1080/13600800600751044

Lori, G. (2009) University Students' Perceptions of Plagiarism, The Journal of Higher Education, 80 (6). 
Lowe, H. \& Cook, A. (2003) Mind the Gap: Are students prepared for Higher Education, Journal of Further and Higher Education, 27 (1), 53 - 76. DOI:10.1080/03098770305629

Lumsden, Eunice, Mcbryde-Wilding, Heather \& Rose, Hannah (2010) Collaborative practice in enhancing the first year student experience in Higher Education, Enhancing the Learner Experience in Higher Education, 2 (1), 12-24.

Marton, F. \& Säaljö, R. (1976). Symposium: Learning processes and strategies. On qualitative differences in learning. II: Outcome as a function of the learner's conception of the task, British Journal of Educational Psychology, 46, 115-127. DOI: 10.1111/j.20448279.1976.tb02304

Miller, T. E., Bender, B. E., \& Schuh, J. H. (2005). Promoting reasonable expectations: Aligning student and institutional views of the college experience. Centers for Teaching and Technology - Book Library. Paper 76.

Mulliner, E. \& Tucker, M. (2015). Feedback on feedback practice: perceptions of students and academics, Assessment and Evaluation in Higher Education, 1-23. DOI:

$10.1080 / 02602938.2015 .1103365$

Owens, C. \& White, F. (2013) A 5-year systematic strategy to reduce plagiarism among firstyear psychology university students, Australian Journal of Psychology, 65, 14-21. DOI: 10.1111/ajpy.12005

Owunwanne, D., Rustagi, N. \& Dada, R. (2010) Students' Perceptions of Cheating and Plagiarism in Higher Institutions, Journal of College Teaching \& Learning, 7 (11), 59-68. 
Pithers, B. \& Holland, T. (2006). Student Expectations and the Effect of Experience. Australian Association for Research in Education Conference, Adelaide, Australia. Retrieved April 13, 2014, from http://www.aare.edu.au/06pap/pit06290.pdf

Sander, P., Stevenson, K., King, M. \& Coates, D. (2000) University Students' Expectations of Teaching, Studies in Higher Education, 25 (3), 309-323. DOI:

$10.1080 / 03075070050193433$

Slaughter, K. \& Bates, S. (2009) Mapping the transition - Content and pedagogy across the school-university boundary, New Directions, 5, 35-39.

Steele, C. (1992) Race and the schooling of black Americans, in: E. Krupat (Ed.), Psychology is Social: readings and conversations in social psychology (3rd ed) (New York: Harper Collins).

Stevenson, K., \& Sander, P. (1998). How do Open University Students Expect to be Taught at Tutorials? Open Learning, 13 (2), 42-46. DOI: 10.1080/0268051980130208

Surgenor, P.W.G. (2013) Measuring up: comparing first year students' and tutors' expectations of assessment, Assessment \& Evaluation in Higher Education, 38 (3), 288-302. DOI:10.1080/02602938.2011.630976

Trotter, E. \& Roberts, C. A. (2006) Enhancing the early student experience, Higher Education Research \& Development, 25, 371-386. DOI: 10.1080/07294360600947368

Wilkins, S., Shams, F. \& Huisman, J. (2013) The decision-making and changing behavioural dynamics of potential higher education students: the impacts of increasing tuition fees in England, Educational Studies, 39 (2), 125-141. DOI: 10.1080/030556918.2012.681360 
Williams, J. \& Kane, D. (2008) Exploring the National Student Survey: Assessment and feedback issues (York: The Higher Education Academy).

Wilson F., Child, S. \& Suto I. (2016) Assessing the transition between school and university:

Differences in assessment between A level and university in English, Arts \& Humanities in Higher Education, DOI: 10.1177/1474022216628302

Wingate, U. (2007) A framework of transition: supporting 'learning to learn' in higher education, Higher Education Quarterly, 61, 391-405. DOI: 10.1111/j.14682273.2007.00361.x

Yorke, M. \& Longden, B. (2008) The first-year experience of higher education in the UK: Final report of a project funded by the higher education Academy (York: The Higher Education Academy). Available online at:

https://www.heacademy.ac.uk/sites/default/files/fyefinalreport_0.pdf (accessed 2 February 2015).

Yorke, M. \& Thomas, L. (2003). Improving the Retention of Students from Lower Socioeconomic Groups. Journal of Higher Education Policy and Management, 25 (1), 63-74. DOI: $10.1080 / 13600800305737$ 
Table 1 Percent of students giving each response, combined for the two cohorts, on perception of verbal feedback

\section{Response}

At university how often do Always Often Sometimes Rarely Never you expect to get: 
Personal verbal feedback

$19.1 \quad 35.9$

31.6

12.1

1.4

on an essay assignment

Verbal feedback to the

$16.2 \quad 38.3$

33.5

10.4

1.6

whole class on an essay

assignment

Personal verbal feedback

$15.1 \quad 37.8$

33.7

11.8

1.6

on a practical report

Verbal feedback to the

$14.5 \quad 38.9$

36.1

8.5

2.1

whole class on a practical

report.

Table 2. Combined cohorts; mean percentage of students ranking each type of feedback in order of value to them

Percentage of students giving each rank

\begin{tabular}{lccccc}
$\quad$ Type of feedback & 1st & 2nd & 3rd & 4th & 5th \\
\hline Overall mark & 24.4 & 16.3 & 25.0 & 18.5 & 15.8 \\
Written corrections on & 2.0 & 6.6 & 11.4 & 25.3 & 54.7 \\
spelling and grammar & & & & &
\end{tabular}


content of the work

Written corrections to style

13.8

25.1

39.4

17.0

and format of the work

Verbal feedback from the

19.1

10.7

10.1

person marking the work

Figure legends

Figure 1. Responses to: At school, in science subjects, how often do you get verbal feedback. Black bars represent the 2006 cohort, grey bars represent the 2013 cohort.

Figure 2. Responses to: At school, in subjects other than science, how often do you get verbal feedback. Black bars represent the 2006 cohort, grey bars represent the 2013 cohort. 
Figure 3. Responses to: At school, when essays are marked, I would lose marks if I did not put material directly from the internet into my own words. Black bars represent the 2006 cohort, grey bars represent the 2013 cohort.

Figure 4. Responses to: At school, in science subjects, how often is a draft commented on before you hand in a final version. Black bars represent the 2006 cohort, grey bars represent the 2013 cohort.

Figure 5. Responses to: At university, if an essay is set, how often do you expect a draft to be commented on before you hand in a final version. Black bars represent the 2006 cohort, grey bars represent the 2013 cohort.

Figure 6. Combined data for both cohorts comparing responses for school and university to the question: 'how often are deadlines strictly adhered to. Black bars represent the response for school and grey bars represent the response for university.

Figure 7 Responses to: At university, I expect all assignments to be assessed. Black bars represent the 2006 cohort, grey bars represent the 2013 cohort.

Figure 8 Responses to: I expect the person who sets the assignment to be the person who marks it. Black bars represent the 2006 cohort, grey bars represent the 2013 cohort. 